\title{
The Age of the Air in the Firn and the Ice at Summit, Greenland
}

\author{
J. Schwander, ${ }^{1}$ J.-M. Barnola,${ }^{2}$ C. Andrié, ${ }^{3}$ M. Leuenberger, ${ }^{1}$ A. Ludin, ${ }^{1}$ \\ D. RaYNAUd, ${ }^{2}$ AND B. STAUfFER ${ }^{1}$
}

\begin{abstract}
In the framework of the Eurocore drilling project 1989 at Summit, Central Greenland, air samples were collected from a drill hole in the firn at several depth levels. The samples have been analyzed for ${ }^{85} \mathrm{Kr}, \mathrm{CO}_{2}, \mathrm{CH}_{4}, \mathrm{CFC}$ 's (F-11 and F-12) contents and for the isotopic composition of nitrogen and oxygen. The measured data are compared with the results of a diffusion model. $\mathrm{CO}_{2}$, for example, takes 12 years (with a standard deviation of 7.5 years) to diffuse from the surface to the firn-ice transition under the present climatic conditions at Summit. The difference between the age of the ice and the mean age of the occluded air is approximately 210 years. An enrichment of the heavier isotopes due to separation by gravity has been observed. Molecular diffusion alone suffices to explain the observed concentration trends in the firn column. We can, however, not exclude the existence of a convective zone below the surface. We have also measured the density and closed porosity along the firn core that has been retrieved when drilling the hole. The porosity data reveal that the air is occluded into bubbles mainly between 65 and $80 \mathrm{~m}$, corresponding to densities of 790 and $830 \mathrm{~kg} / \mathrm{m}^{3}$, respectively.
\end{abstract}

\section{INTRODUCTION}

The potential of glaciers and polar ice sheets as an archive for the history of climate, volcanism, atmospheric chemistry, and other parameters has been well recognized. The archive has basically three types of records. The first type is the ice itself (isotopic composition, fabrics), the second consists of the solid and dissolved impurities trapped in the ice, and the third is the composition of the air in the bubbles of the ice. There is a basic difference between the third type and the two other types of records. While the isotopic composition and the impurities measured in an ice sample originate from the precipitation event that has led to the specific layer of ice from which the sample was taken, the air in the bubbles of that ice has a different age. The air is occluded into bubbles only at the depth of the firn-ice transition, typically somewhere between 50 and $100 \mathrm{~m}$ [Schwander and Stauffer, 1984]. In the firn above this transition the air can exchange through a system of interconnected pores that are open to the atmosphere at the snow surface. The knowledge of this age difference is important for the reconstruction of the evolution of atmospheric trace gases, and when comparing the air composition in the bubbles with records of the first and second type. The age of the air in an ice sample cannot be expressed as a single number, but has a rather broad distribution due to the diffusive and convective mixing of the air in the firn layer and to the gradual occlusion of the bubbles within the close-off region. In order to assess the age difference and distribution, we must know the depth and extent of the bubble close-off region and the mixing of the air in the pore system of the firn. The depth interval where enclosure occurs has been mea-

\footnotetext{
${ }^{1}$ Physics Institute, University of Bern, Bern, Switzerland.

${ }^{2}$ Laboratoire de Glaciologie et Géophysique de l'Environnement, Saint Martin d'Heres Cedex, France.

${ }^{3}$ Laboratoire d'Océanographie Dynamique et de Climatologie, Institut Français de Recherche Scientifique pour le Développement en Cooperation, Université Pierre et Marie Curie, Paris Cedex, France.
}

Copyright 1993 by the American Geophysical Union.

Paper number 92JD02383.

0148-0227/93/92JD-02383\$05.00 sured at Siple Station (Antarctica) and has been estimated for other sites by assuming that the enclosure always occurs within the same range of firn density [Schwander and Stauffer, 1984]. The mixing by molecular diffusion in the firn has been calculated with a model [Schwander et al., 1988], permitting an estimate of the age difference and distribution for cold polar sites.

In the framework of the Eurocore drilling project in summer 1989 at Summit, Greenland $\left(72.58^{\circ} \mathrm{N}, 37.64^{\circ} \mathrm{W}\right)$, we investigated the closed-off interval, took air samples from different depths in the firn, and measured the concentrations of ${ }^{85} \mathrm{Kr}, \mathrm{CO}_{2}, \mathrm{CH}_{4}, \mathrm{CCl}_{3} \mathrm{~F}(\mathrm{~F}-11), \mathrm{CCl}_{2} \mathrm{~F}_{2}(\mathrm{~F}-12)$, as well as the isotopic composition of $\mathrm{N}_{2}$ and $\mathrm{O}_{2}$, expressed as $\delta^{15} \mathrm{~N}$ and $\delta^{18} \mathrm{O}$. To our knowledge this is the first time that firn air has been sampled and analyzed over the whole column height. The validity of the diffusion model can be tested by comparison with these data. Specifically, we can estimate the role of convection. Turbulent mixing due to wind pumping and thermal gradients in a zone below the surface would increase the mixing rate compared to pure molecular diffusion.

\section{Experimental Techniques and Model}

For the determination of the density and the closed porosity, we cut cylindrical samples of 40 - to $50-\mathrm{mm}$ diameter and 40 - to $50-\mathrm{mm}$ height on a lathe. The density was determined by measuring the dimensions and weight of the samples. The closed porosity, defined as the ratio between the volume of sealed-off pores and the bulk volume of the sample, was determined by measuring the volume of the air that is displaced when the sample is put in a calibrated cell. We used two different instruments, one made in Bern and the other in Grenoble. The equipment from Bern had already been used for the measurements on the ice core from Siple Station, Antarctica, and has been described by Stauffer et al. [1985a]. All measurements were made in the field. The temperature was approximately $-15^{\circ} \mathrm{C}$ and we used a pure ice density of $918.5 \mathrm{~kg} / \mathrm{m}^{3}$ [Bader, 1964] for the calculation of the porosity. The precision of the density and porosity measurements is $\pm 2 \mathrm{~kg} / \mathrm{m}^{3}$ and \pm 0.002 , respectively. One has, however, to keep in mind that the porosity data depend on the sample size. The smaller the sample, the higher the 


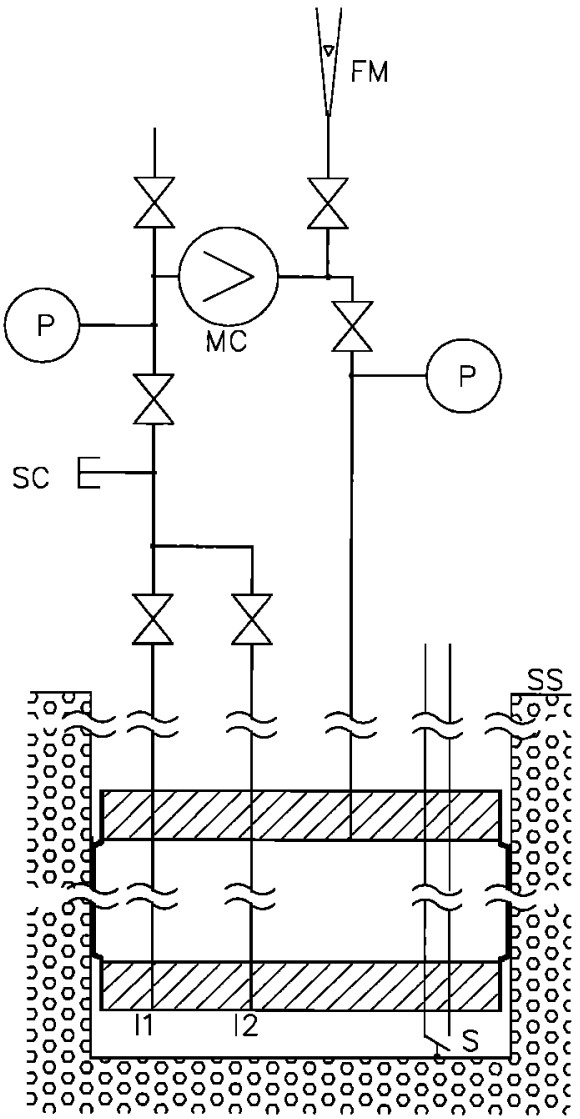

Fig. 1. Schematic of air sampling equipment. FM, flowmeter; I1, I2, air inlets; MC, membrane compressor; P, pressure gauge; S, bottom detector switch; SC, sampling connector; SS, snow surface. The borehole is sealed by inflating the 5 -m-long outer rubber tube that connects the two end plates.

number of cut closed pores or pore clusters when preparing the sample.

A tubing system, shown schematically in Figure 1, was used to extract air from the firn. Two different $6-\mathrm{mm}$ id plastic tubes served to collect the samples, one made of polyamide with regard to its low gas permeability and the other made of butyl nitrile rubber in order to minimize freon contamination. When we had reached the sampling depth, we lowered the tubing system into the drill hole immediately after the last core had been recovered. After sealing the hole by inflating the 5 -m-long outer rubber tube, we pumped about $1 \mathrm{~m}^{3}$ of air with a membrane compressor from the bottom of the hole. Both sampling tubes were kept open. This procedure brought uncontaminated air from the firn to the sampling tubes. One of the sampling tubes was then closed, and a flask was filled through the other. Then we switched to the other tube and flushed it before taking another sample. The flow rate through each tube was about $0.25 \mathrm{~L} / \mathrm{s}$, which led to a residence time of the air in the 100 -m-long tube of about $11 \mathrm{~s}$. The samples were either collected by expansion into previously evacuated stainless steel flasks or compressed to approximately 3 bars with the aid of a second membrane compressor. At $90 \mathrm{~m}$, that is below the close-off depth, we tested the system for tightness by creating a vacuum in the bore hole. Assuming the same performance of the system at all sampling depths, we calcu- lated that the worst case contamination with air leaking out of the pressurized tube or along its outside wall was for all samples less than $1 \%$.

$\mathrm{CO}_{2}$ and $\mathrm{CH}_{4}$ have been measured both in Bern and Grenoble with a gas chromatograph (GC). These measurements have been intercalibrated by a standard gas comparison. The $\mathrm{CO}_{2}$ concentration has also been adjusted to the $\mathrm{CO}_{2}$ standard used by the Scripps Institution of Oceanography, La Jolla, California. The $\mathrm{CH}_{4}$ concentration has been adjusted to the standard used by the Institute für Atmosphärenchemie, Jülich, Germany. The standard error of a single $\mathrm{GC}$ measurements is about 1.5 ppmv for $\mathrm{CO}_{2}$ and 25 ppbv for $\mathrm{CH}_{4}$. Usually two or three measurements were made on each sample, and thus we reached a precision of about 1 ppmv for $\mathrm{CO}_{2}$ and 15-20 ppbv for $\mathrm{CH}_{4}$. Possible systematic shifts due to the sampling procedure or the interaction with the flask material are not included. The ${ }^{85} \mathrm{Kr}$ was measured in Bern using a standard counting technique. The concentration of Krypton in the counter was determined by mass spectrometry. The chlorofluorocarbons (CFC's) were analyzed with a GC at the Laboratoire d'Océanographie Dynamique et de Climatologie (LODYC), Paris. The CFC was calibrated against a primary standard from the Scripps Institution of Oceanography (precision 0.5\%). Nevertheless, the low pressure of the samples did not allow very precise measurements. The $\delta^{15} \mathrm{~N}$ of $\mathrm{N}_{2}$ and $\delta^{18} \mathrm{O}$ of $\mathrm{O}_{2}$ have been measured with mass spectrometry in Bern. The analytical precision is $0.03 \%$.

We used a one-dimensional diffusion model to calculate the expected concentrations in the firn as a function of depth. The model is based on pure molecular diffusion and takes into account the influence of gravity [Schwander, 1989; Craig et al., 1988], which leads to an increase in the heavier components in deeper strata. We did not consider any possible additional mixing due to convection or ventilation by wind or pressure variations.

For the model, the firn column was divided into about 200 boxes, each of which contains the same mass of air. The length of the boxes thus increases with depth. The large number of boxes is required because the diffusion coefficient changes orders of magnitudes from near the surface to the bubble close-off region. To determine the size of the boxes, we approximated the firn porosity with a density formula by Herron and Langway [1980]. The uppermost box is in equilibrium with the atmosphere. The flux $j$ of a certain air component is given by

$$
j=j_{\text {diffusion }}+j_{\text {gravity }}=-D\left(\frac{\partial c}{\partial z}+\frac{m g c}{k T}\right)
$$

After a finite time step $\Delta t$, the concentration change $\Delta c$ in box $i$ (numbered from top to bottom) is

$$
\Delta c_{i} \approx \Delta t D_{i}\left(\frac{c_{i-1}-2 c_{i}+c_{i+1}}{\Delta z^{2}}+\frac{m g\left(c_{i-1}-c_{i+1}\right)}{2 k T \Delta z}\right)-\Delta t c_{i} \lambda
$$

where $c_{i}$ is concentration of the considered gas in box $i, m$ is molecular mass of gas, $D_{i}$ is the diffusion coefficient at level $i, g$ is acceleration of gravity, $k$ is the Boltzmann constant, $T$ is mean temperature, $\Delta z$ is length of box $i$, and $\lambda$ is the decay constant for radioactive gas.

To constrain the model, we used the following data and boundary conditions. The diffusion coefficient of $\mathrm{CO}_{2}$ in firn 
was measured on the Siple Station firn core [Schwander et $a l ., 1988$ ], and we assumed that it would show roughly the same density dependence at Summit, although the climatic conditions at Siple Station are somewhat different from Central Greenland. The diffusivity depends on the open porosity and the tortuosity. The closed porosity versus density relation of the two sites is rather similar (Figure 2), and so must the open porosity versus density relation. Since both locations, Siple and Summit, are polar locations where surface melting under present climatic conditions is rare, the firnification is controlled by the same, dry sintering process. This is a good reason to assume a similar tortuosity at both sites, and hence the assumption made on the diffusion coefficient is probably justified. The diffusion coefficient has been corrected for the mean temperature and pressure as observed at Summit [Landolt-Börnstein, 1969], and for gases other than $\mathrm{CO}_{2}$, we applied a corrective factor according to the relative diffusivities. The other input data for the model are summarized in Table 1 . The $\mathrm{CO}_{2}$ and $\mathrm{CH}_{4}$ concentrations in the air at Summit were assumed to be equal to the concentrations reported for Alert Station, Canada [Trivett and Worthy, 1989]. Concentrations for the last 100 years have been calculated based on the measured atmospheric concentrations on Mauna Loa for $\mathrm{CO}_{2}$ [Keeling et al., 1989] and on worldwide averaged data for $\mathrm{CH}_{4}$ [Blake and Rowland, 1988; Steele et al., 1987]), and the results from the analysis of the Siple Station ice core [Neftel et al., 1985;


Fig. 2. (a) Density (circles) and closed porosity (triangles) versus depth. The data obtained with the Grenoble instruments are represented with open symbols, those measured with the Bern instruments with solid symbols. Solid line: Density according to the empirical model by Herron and Langway [1980] with the parameter set $T=-31^{\circ} \mathrm{C}$, accumulation $0.209 \mathrm{~m}$ water $/ \mathrm{yr}$, surface density 340 $\mathrm{kg} / \mathrm{m}^{3}$. (b) Closed porosity versus density. Solid line is the smoothed spline through Grenoble data; dashed line is the smoothed spline through data from Siple Station [Schwander and Stauffer, 1984]. Symbols are as in Figure $2 a$.
TABLE 1a. Parameters Used for the Diffusion Model: Present Climatic Parameters for Summit

\begin{tabular}{lc}
\hline \multicolumn{1}{c}{ Parameter } & Value \\
\hline Accumulation rate, $\mathrm{m} \mathrm{H}_{2} \mathrm{O} / \mathrm{yr}$ & 0.209 \\
Mean temperature, ${ }^{\circ} \mathrm{C}$ & -31 \\
Mean barometric pressure, $\mathrm{hPa}$ & 665 \\
Firn density close to surface, $\mathrm{kg} / \mathrm{m}^{3}$ & 340 \\
\hline
\end{tabular}

Stauffer et al., 1985b]. We have assumed the seasonal variations to be the same as at Alert Station, Canada. The ${ }^{85} \mathrm{Kr}$ concentration at Summit is based on data from various northern hemispheric stations [Rozanski, 1979; Weiss et al., 1992] and general circulation model (GCM) calculations [Jacob et al., 1987]. The mixing ratios of the CFC's F-11 and F-12 have been assumed to be equal to the mean northern hemispheric figures.

We ran the diffusion model for an integration time of about 100 years preceding June 1989. After a certain number of time steps, the content of all boxes is shifted downward by one box to take into account that some air is trapped at the bubble close-off depth and then carried along with the ice flow. This latter procedure is important if the firnification is fast, that is, for relatively warm areas with a high snow accumulation rate or when measuring parameters with very high precision. For this investigation at Summit it could have been omitted, since the effect is small compared to the standard errors of our measurements.

\section{Results AND Discussion}

The depth profile of the density and the closed porosity are shown in Figure $2 a$ together with a density curve computed with the model by Herron and Langway [1980]. The mean annual accumulation rate for the last 200 years has been determined to $0.228 \mathrm{~m}$ ice equivalent $(0.209 \mathrm{~m}$ water equivalent) based on the density measurements and the depth of the acid layer from the Laki eruption in 1783 AD (C. U. Hammer, personal communication, 1989). The data show that the air is occluded mainly between 65 and $80 \mathrm{~m}$ corresponding to densities between 790 and $830 \mathrm{~kg} / \mathrm{m}^{3}$. This does not mean that there is mixing down to $80 \mathrm{~m}$. The occlusion of the air is an erratic process. Air tight layers already occur at shallower depths and could isolate deeper but still permeable ones. Figure $2 b$ indicates that there is a close relation between the density and the closed porosity. The Grenoble and Bern data sets agree well. A smoothed spline curve is plotted through the Grenoble data. The Bern data have not been used for the spline calculation because the number of data points is much smaller than in the Grenoble data set, and they are unevenly spaced. A similar relation between closed porosity and density has been found for the firn at Siple Station, Antarctica, measured with the Bern equipment [Schwander and Stauffer, 1984]. The smoothed spline curve through the Siple Station data is overlaid on Figure $2 b$.

Based on the closed porosity data from Summit, Martinerie et al. [1992] estimated the mean bubble close-off density to be about $818 \mathrm{~kg} / \mathrm{m}^{3}$, yet with a rather high uncertainty. This density corresponds to a depth of $75 \mathrm{~m}$. Based on total gas measurements made on various polar ice cores, Martinerie et al. have shown a correlation between mean temper- 
TABLE $1 b$. Parameters Used for the Diffusion Model: Measured Air Components

\begin{tabular}{|c|c|c|c|}
\hline & $\begin{array}{l}\text { Mole } \\
\text { Mass }\end{array}$ & $D / D\left(\mathrm{CO}_{2}\right)^{a}$ & References for the History of the Trace Gas Concentration \\
\hline${ }^{85} \mathrm{Kr}$ & 85 & $0.88^{b}$ & Jacob et al. [1987], Rozanski [1979], Weiss et al. [1992] ${ }^{d}$ \\
\hline $\mathrm{CO}_{2}$ & 44 & & Trivett and Worthy [1989], Keeling et al. [1989], Neftel et al. [1985] $]^{e}$ \\
\hline $\mathrm{CH}_{4}$ & 16 & $1.35^{b}$ & $\begin{array}{l}\text { Trivett and Worthy [1989], Blake and Rowland [1988], Stauffer et al. } \\
{[1985 b], \text { Steele et al. }[1987]^{f}}\end{array}$ \\
\hline F-11 & 137 & $0.51^{c}$ & $\begin{array}{l}\text { Chemical Manufacturers Association [1984], Cunnold et al. [1986], } \\
\text { Ehalt et al. [1989], Chanin et al. [1990] }\end{array}$ \\
\hline F-12 & 121 & $0.58^{c}$ & $\begin{array}{l}\text { Chemical Manufacturers Association [1984], Cunnold et al. [1986], } \\
\text { Ehalt et al. [1989], Chanin et al. [1990] }\end{array}$ \\
\hline $\begin{array}{l}\mathrm{N}_{2} \\
\mathrm{O}_{2}\end{array}$ & $\begin{array}{l}28 ; 29 \\
32 ; 34\end{array}$ & $\begin{array}{l}1.21^{b} \\
1.29^{b}\end{array}$ & \\
\hline \multicolumn{4}{|c|}{ 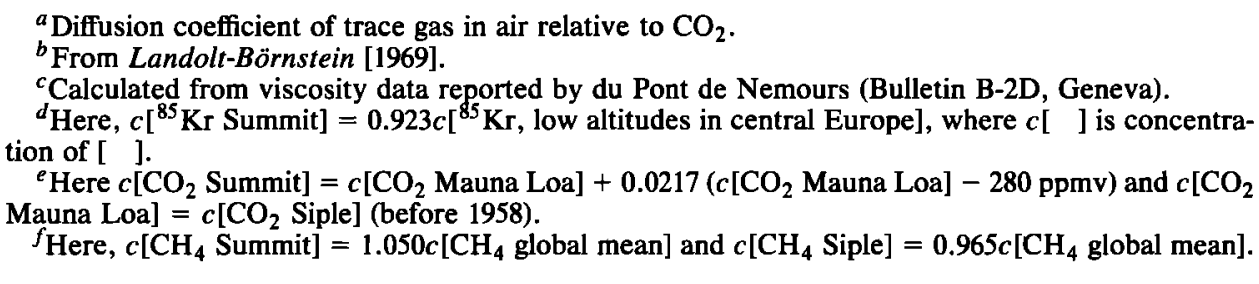 } \\
\hline
\end{tabular}

ature and bubble close-off density. Accordingly, at Summit, where the mean annual temperature is about $-31^{\circ} \mathrm{C}$, we would expect a closed-off density of about $824 \mathrm{~kg} / \mathrm{m}^{3}$, corresponding to a depth of $78 \mathrm{~m}$. The uncertainty is about 2 $\mathrm{m}$. Taking into account the high uncertainty of the estimation from the porosity data, the closed-off depth at Summit is thus compatible with the general trend as observed for polar sites.

The results of the ${ }^{85} \mathrm{Kr}, \mathrm{CO}_{2}, \mathrm{CH}_{4}, \mathrm{~F}-11$, and $\mathrm{F}-12$ concentrations in the air samples extracted from the firn are summarized in Table 2 and plotted in Figure 3. All trace gas concentrations decrease with depth. It is obvious to attribute this to the increasing trend of the trace gas mixing ratios in the atmosphere. These gradients in the concentrations within the permeable upper $70 \mathrm{~m}$ also reveal that the ventilation time of the air in the firn is considerable. The concentrations of ${ }^{85} \mathrm{Kr}, \mathrm{CO}_{2}$, and $\mathrm{CH}_{4}$ measured at $70-\mathrm{m}$ depth correspond to atmospheric concentrations around 10-12 years ago.

Due to its half-life of 10.8 years and the rapid increase in its atmospheric mixing ratio, ${ }^{85} \mathrm{Kr}$ is an excellent tracer to investigate the ventilation of the firn. With two exceptions, the measured ${ }^{85} \mathrm{Kr}$ data are within 1 standard deviation, the same as the values expected from the diffusion model. The two exceptions, at 60 and $79 \mathrm{~m}$, are more than 3 standard deviations higher than the model. It is very improbable that this is due to statistical scatter alone. More likely, there is a systematic reason, that is, either contamination with younger air or an inadequacy of the model. There is not much freedom to adjust the model parameters, as this would lead to conflicts with the other measurements. A small contamination with fresh air is therefore more probable.

With one exception, the Bern and Grenoble values are comparable in terms of $\mathrm{CO}_{2}$. In the case of $\mathrm{CH}_{4}$, the Grenoble values are generally higher than the Bern values, and this discrepancy cannot be from the different standard gases, since they have been intercalibrated. No firm explanation has been found, but the most likely reason seems to be linked to the sampling. At 60-, 70-, and 79-m depth, we took two samples through the polyamide tube (Table 2), one after pumping only $0.5 \mathrm{~m}^{3}$ air through the tube and the other after the usual $1 \mathrm{~m}^{3}$ of flushing air was sucked up (at $79 \mathrm{~m}$, only $0.12 \mathrm{~m}^{3}$ and $0.16 \mathrm{~m}^{3}$, respectively, due to the lower permeability of the firn at this depth). The second sample shows generally lower $\mathrm{CO}_{2}$ and $\mathrm{CH}_{4}$ concentrations. Unfortunately, we did not have enough sample flasks to perform an extensive test to determine the optimum flushing time. Nevertheless, it is possible to check the quality of sampling: at two levels, the $\mathrm{CO}_{2}$ data can be compared with independent values. At the surface we can estimate the expected atmospheric value from recent data measured at atmospheric sampling stations (surface boundary condition for

TABLE 2a. Sample Collection Procedure

\begin{tabular}{|c|c|c|c|c|}
\hline & Method & $\begin{array}{c}\text { Flask Volume, } \\
\mathrm{mL}\end{array}$ & $\begin{array}{l}\text { Tubing } \\
\text { Used }\end{array}$ & $\begin{array}{c}\text { Pumping Time } \\
\text { Before Collection, } \\
\text { min }\end{array}$ \\
\hline Bern & expansion & 50 & polyamide & $60(20)$ \\
\hline Short & expansion & 50 & polyamide & 30 (15) \\
\hline Large & compressed & 3400 & polyamide & $60(20)$ \\
\hline $\begin{array}{l}\text { Grenoble } \\
\text { Ice }\end{array}$ & $\begin{array}{l}\text { compressed } \\
\text { air extracted from }\end{array}$ & 75 & butyl nitrile & $60(20)$ \\
\hline
\end{tabular}

Before collecting the samples, the tubing was flushed during the time indicated at a rate of $15 \mathrm{~L} / \mathrm{min}$ except at $79 \mathrm{~m}$, where the pumping rate was limited to $8 \mathrm{~L} / \mathrm{min}$ due to the low permeability of the firn at this depth.

*Values in parentheses apply for 79-m depth. 
TABLE $2 b$. Composition of Air Samples Extracted in June 1989 From the Firn

\begin{tabular}{|c|c|c|c|c|c|c|c|c|c|c|c|c|}
\hline \multirow[b]{2}{*}{ Component } & \multirow[b]{2}{*}{ Sample } & \multicolumn{10}{|c|}{ Depth, m } & \multirow{2}{*}{$\begin{array}{c}\text { Date of } \\
\text { Analysis }\end{array}$} \\
\hline & & $\mathbf{0}$ & 10 & 20 & 30 & 40 & 50.5 & 60 & 70 & 79 & 89.6 & \\
\hline \multirow[t]{4}{*}{$\mathrm{CO}_{2}, \mathrm{ppmv}$} & $\begin{array}{l}\text { BE } \\
\text { BE(short) }\end{array}$ & 356.1 & 360.7 & 356.9 & 350.9 & 352.6 & 348.9 & $\begin{array}{l}345.2 \\
350.7\end{array}$ & $\begin{array}{l}340.4 \\
243.3\end{array}$ & $\begin{array}{l}321.1 \\
318.4\end{array}$ & \multirow{16}{*}{300.5} & Aug. 1989 \\
\hline & $\mathrm{BE}(1 \mathrm{yr})$ & 373.8 & & & & & & & 435.7 & 344.6 & & Aug. 1990 \\
\hline & BE(large) & & & 641.4 & & 362.2 & & 363.2 & 344.5 & 323.9 & & Aug. 1990 \\
\hline & $\begin{array}{l}\text { GRE } \\
\text { GRE(ice) }\end{array}$ & 359 & & 347 & 354.6 & 349 & 352.7 & 346 & & $\begin{array}{l}316 \\
314\end{array}$ & & Sept. 1989 \\
\hline \multirow[t]{5}{*}{$\mathrm{CH}_{4}, \mathrm{ppmv}$} & $B E$ & 1.826 & 1.837 & 1.723 & 1.816 & 1.731 & 1.799 & 1.761 & 1.684 & 1.240 & & Aug. 1989 \\
\hline & BE(short) & & & & & & & 1.728 & 1.686 & 1.156 & & Aug. 1989 \\
\hline & BE(lyr) & 1.802 & & & & & & & 1.648 & 1.181 & & Aug. 1990 \\
\hline & BE(large) & & & 1.775 & & 1.815 & & 1.675 & 1.685 & 1.165 & & Aug. 1990 \\
\hline & GRE & 1.770 & & 1.850 & 1.820 & 1.820 & 1.970 & 1.860 & & 1.260 & & Sept. 1989 \\
\hline $\begin{array}{c}{ }^{85} \mathrm{Kr}, \mathrm{Bq} / \mathrm{m}^{3} \\
\text { air }\end{array}$ & $\begin{array}{l}\text { GRE(ice) } \\
\text { BE(large) }\end{array}$ & & & 0.913 & & 0.612 & & 0.554 & 0.302 & 0.052 & & June $1991^{*}$ \\
\hline F-11, pptv & GRE & 321 & & 320 & & & 306 & 222 & & 16 & & Nov. 1990 \\
\hline $\mathrm{F}-12, \mathrm{pptv}$ & GRE & 518 & & 510 & & & 367 & 244 & & 18 & & Nov. 1990 \\
\hline \multirow[t]{2}{*}{$\delta^{15} \mathrm{~N}, \%$} & $\mathrm{BE}$ & & & 0.07 & & 0.17 & & 0.30 & 0.33 & & & April 1991 \\
\hline & BE(large) & & & 0.21 & & 0.29 & & 0.42 & 0.45 & 0.46 & & \\
\hline \multirow{2}{*}{$\delta^{18} \mathrm{O}, \%$} & $\mathrm{BE}$ & & & 0.23 & & 0.51 & & 0.76 & 0.88 & & & April 1991 \\
\hline & BE(large) & & & 0.44 & & 0.59 & & 0.76 & 0.84 & 0.84 & & \\
\hline
\end{tabular}

BE, Bern; GRE, Grenoble. The table includes two results for $\mathrm{CO}_{2}$ and one for $\mathrm{CH}_{4}$ from ice samples.

${ }^{* 85} \mathrm{Kr}$ data are decay corrected for June 1989 (half-life 10.76 years).

model), and at $79 \mathrm{~m}$ we measured the $\mathrm{CO}_{2}$ concentration on an ice sample. At both levels the mean $\mathrm{CO}_{2}$ concentrations of the flask samples were 4 ppmv higher than the expected atmosphere and ice sample values, respectively. Those 4 ppmv are consistent with the uniform shift observed between the smoothed curve through the data points and the model results (Figure 3), indicating a small and rather constant contamination with $\mathrm{CO}_{2}$. Except for this shift, the level of confidence for the $\mathrm{CO}_{2}$ data is apparently high. Even a $\mathrm{CO}_{2}$ winter maximum at about $10 \mathrm{~m}$ below the surface is discernible, although the precision and density of the data are not sufficient unequivocal evidence. For $\mathrm{CH}_{4}$ the relative errors are larger, and the slope between the surface and $70 \mathrm{~m}$ is not so apparent. Nevertheless, the $\mathrm{CH}_{4}$ results are generally compatible with the other results. For comparison, the extreme case of "instant mixing and sudden close-off" is also shown for $\mathrm{CO}_{2}$ and $\mathrm{CH}_{4}$. In this model the air is occluded at a specific depth, and above this depth the air in the firn pores is assumed to have the same composition as the atmosphere above the surface. The horizontal parts of the dotted lines (Figure 3 ) correspond to the estimated mean atmospheric mixing ratios for 1989 at Summit. Measurements performed 1 year after sampling (Table $2 b$ ) show similar values for $\mathrm{CH}_{4}$ but a significant $\mathrm{CO}_{2}$ increase, possibly due to interference with the water vapor in the flask [Zumbrunn et al., 1982]. This is an explanation for the positive shift observed for the $\mathrm{CO}_{2}$ data.

The CFC data are generally too high compared to the model. For some samples, we cannot exclude either contamination of the samples (teflon ribbon, valves) or contamination during the analytical procedure due to the influence of some laboratory air in the equilibrium loop (low injection pressure). The unrealistic $\mathrm{F}-11 / \mathrm{F}-12$ ratio $(>0.6)$ for samples from $50-\mathrm{m}$ and $60-\mathrm{m}$ depths suggests F-11 contamination. That is why, despite the better analytical precision for the F-11 data, we trust the F-12 data more; this is confirmed in the trend of the F-12 profile, which is closer to that expected from the model than the F-11 profile.

Although there are unexplained experimental errors, the majority of the results are compatible with the model. Specifically, the precision for ${ }^{85} \mathrm{Kr}$ and $\mathrm{CO}_{2}$ is high enough to see a significant slope between 0 and $70 \mathrm{~m}$. This slope is coherent with the model results. The slope of the model data changes abruptly at about $71-\mathrm{m}$ depth. Below that depth the diffusion coefficient is zero according to the densitydiffusivity relation as measured on the Siple core. The good agreement between the model and the data at 79 and $89.6 \mathrm{~m}$ supports the postulation that the exchange with the atmosphere is essentially stopped below $71 \mathrm{~m}$. Molecular diffusion thus suffices to explain the air composition measured in the firn, a statement that had been suggested from the measurement of the air flow dependent diffusion coefficients made on the Siple Station firn core [Schwander et al., 1988]. From the $\mathrm{CO}_{2}, \mathrm{CH}_{4}, \mathrm{~F}-11$, and F-12 measurements, we can, however, not exclude the existence of a convective zone of up to $20 \mathrm{~m}$ below the surface. Whether or not such a zone exists, it would not significantly change the concentrations of these gases, since in the uppermost $20 \mathrm{~m}$, molecular diffusion alone is efficient enough to remove most of the concentration gradients. This means that owing to the analytical errors, we could not discern whether the concentrations in the top $20 \mathrm{~m}$ are constant or not (Figure 3). Only with ${ }^{85} \mathrm{Kr}$, due to its rapidly increasing mixing ratio in the atmosphere and its radioactive decay, would we, in principle, be able to investigate mixing in the uppermost firn zone more accurately. The generally good compatibility between the ${ }^{85} \mathrm{Kr}$ data and model actually suggests a convection zone of significantly less than $20 \mathrm{~m}$. New and more precise measurements must be done in the future to further constrain the range of the possible extent of the convection zone.

Another important implication of our measurements is 


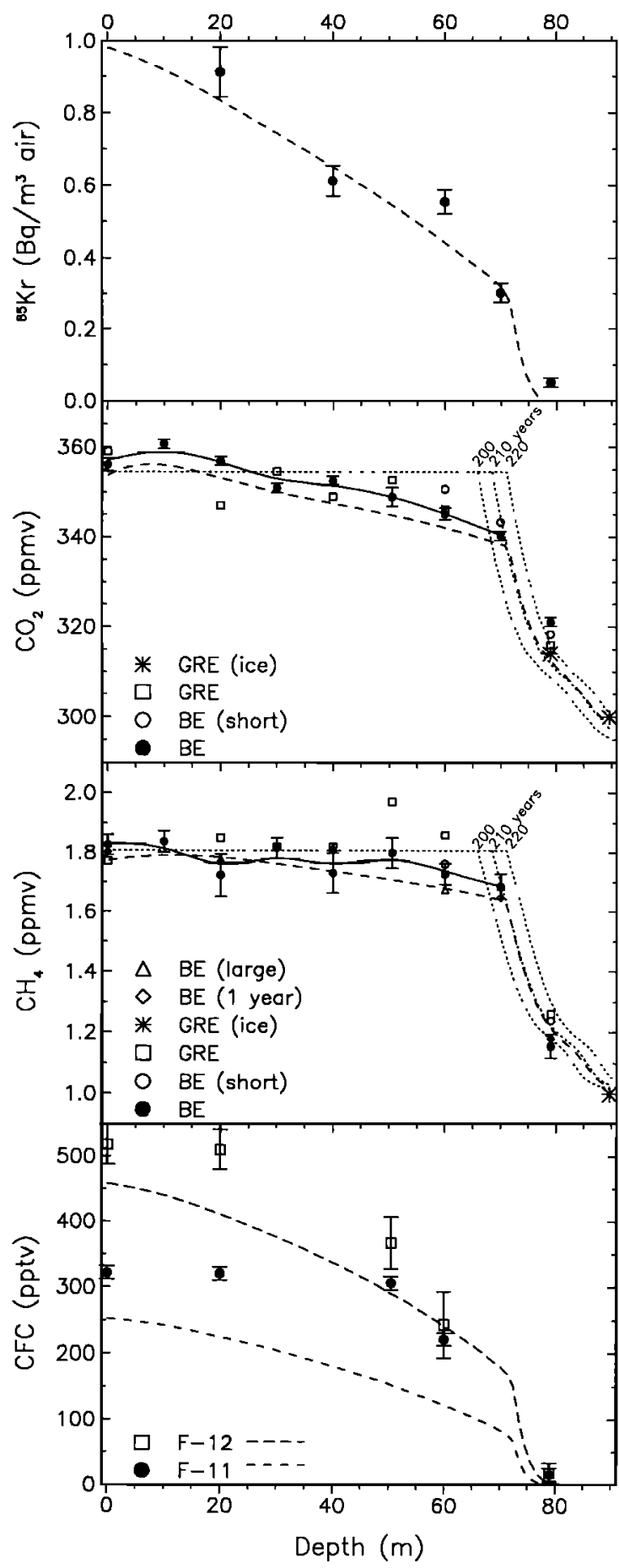

Fig. 3. ${ }^{85} \mathrm{Kr}, \mathrm{CO}_{2}, \mathrm{CH}_{4}$, and $\mathrm{CFC}$ concentrations in the firn and ice. The errors indicated are standard deviations of the laboratory analyses only. The errors of the ${ }^{85} \mathrm{Kr}$ measurements are a little higher than usual due to traces of charcoal dust that escaped from a trap and caused a small memory effect in the separation line. Solid lines are the smoothed spline through the Bern (BE) data. Dashed lines are the diffusion model. Dotted lines in $\mathrm{CO}_{2}$ and $\mathrm{CH}_{4}$ plots are the instant mixing model with three different close-off ages (dating accuracy \pm 1 year).

that diffusion is not impeded by high-density layers like wind crusts: the concentration decreases smoothly down to $70 \mathrm{~m}$, before the slope changes abruptly in the closed-off zone. This confirms our experience from the measurements of the diffusivities on the Siple Station firn core: the presence of wind crusts had no detectable influence on the diffusion coefficient. For the first time we could show that this is also the case for a whole polar firn column.

Colbeck [1989] suggested that wind pumping in the presence of large dunes at the surface of an ice cap could induce an airflow deep down into the firn. In order to effectively exchange the air in the firn at greater depths, the dunes must be sufficiently high with long wavelengths, and strong winds with a dominant direction are required. At Summit, the mean wind speed is $2.7 \mathrm{~m} / \mathrm{s}$, and there is no really dominant wind direction (N. Gundestrup, personal communication, 1992). The surface undulations are estimated to be of the same magnitude or smaller than in Colbeck's example. Colbeck has also assumed a homogeneous permeability in the model. In that case the airflow decreases exponentially with depth. In reality, the air permeability below $20 \mathrm{~m}$ is much lower, leading to a faster decreasing airflow. Taking into account the boundary conditions at Summit, we have estimated the mean airflow in the firn due to wind pumping to be less than $1 \mathrm{~m}^{3} /\left(\mathrm{m}^{2} \mathrm{yr}\right)$ over the whole column, which is not sufficient to compete with the mixing by diffusion. This is confirmed by the good compatibility between model and measurements.

The $\delta^{15} \mathrm{~N}$ measurements provide a measure of the gravitational effect, which occurs in the air in diffusive equilib-



Fig. 4. Effect of gravitation on the mixing ratio and isotopic composition of nitrogen and oxygen. 
rium along a firn column [Sowers et al., 1989]. Figure 4 shows the results, together with the theoretical fractionation due to pure gravitation (in the absence of any convective mixing) versus depth. The samples collected by expansion in 50-mL flasks are in good agreement with the gravitational model. On the other hand, the samples collected by compression in large flasks show a systematic deviation from the model. Since it is hardly conceivable that the isotopic fractionation in the firn column could be larger than in the gravitational equilibrium, these samples have probably undergone additional fractionation during the sampling procedure or handling in the laboratory.

The $\delta^{18} \mathrm{O}$ results are also plotted, showing the gravitational trend. Here the deviations from the model are larger for both kinds of flasks. The $\mathrm{O}_{2} / \mathrm{N}_{2}$ ratios deviate considerably from the atmospheric value. These deviations could stem from outgassing of the 100 -m-long plastic tubing, but it is difficult to understand why one type of flask has almost constant elemental ratios, whereas the other shows an increasing trend with depth. Another possibility would be the interaction with the flask material during storage. As we do not know the nature of these elemental ratio deviations, we cannot judge whether they affect the isotopic composition. Nevertheless, the expected slope in the isotopic fractionation is well reflected by both the $\delta^{15} \mathrm{~N}$ and $\delta^{18} \mathrm{O}$ measurements. These measurements thus further support molecular diffusion as the dominant regime in the major part of the firn column. Convection would destroy the gradient that builds up in diffusive equilibrium in the presence of gravitation and should manifest itself as a zone without isotopic fractionation, extending from the surface down to the level where the convective regime changes to the diffusive regime. Our isotope measurements are unfortunately not consistent enough to draw a conclusion about the thickness of such a convective layer. Sowers et al. [1989, 1992] have reported on $\delta^{15} \mathrm{~N}$ measurements made on air extracted from ice samples of various cores, indicating diffusive column heights that are smaller than the permeable firn zone. These differences vary from core to core and range from near zero up to $30 \mathrm{~m}$. They do not necessarily imply the existence of a convective zone of such thickness, since at least part could be attributed to a nondiffusive zone just above the bubble closed-off depth. Such a zone of about 5-m thickness could explain the difference between the $71 \mathrm{~m}$, where the exchange with the atmosphere stops, and the 75to 78-m closed-off depth as suggested by porosity and total gas measurements [Martinerie et al., 1992].

The composition of the air (reactive components excluded) of cold ice, where its occlusion into bubbles is mainly a mechanical process, is the result of a double convolution. First, the concentration of a gas in a single bubble is determined by the convolution of its age distribution resulting from diffusive mixing, with the evolution of its past atmospheric concentration. A second convolution results from the gradual close off of the pores at the firn-ice transition. This second part is more difficult to deal with, since the diffusivity in this zone becomes very small and is irregular, e.g., layers of low porosity form a seal above deeper but still permeable ones. Since the precision and number of data are too poor to perform a deconvolution of the measured concentration profiles, the application of a diffusion model is at present probably the best way to obtain the age distribution of the air in the firn and ice. The
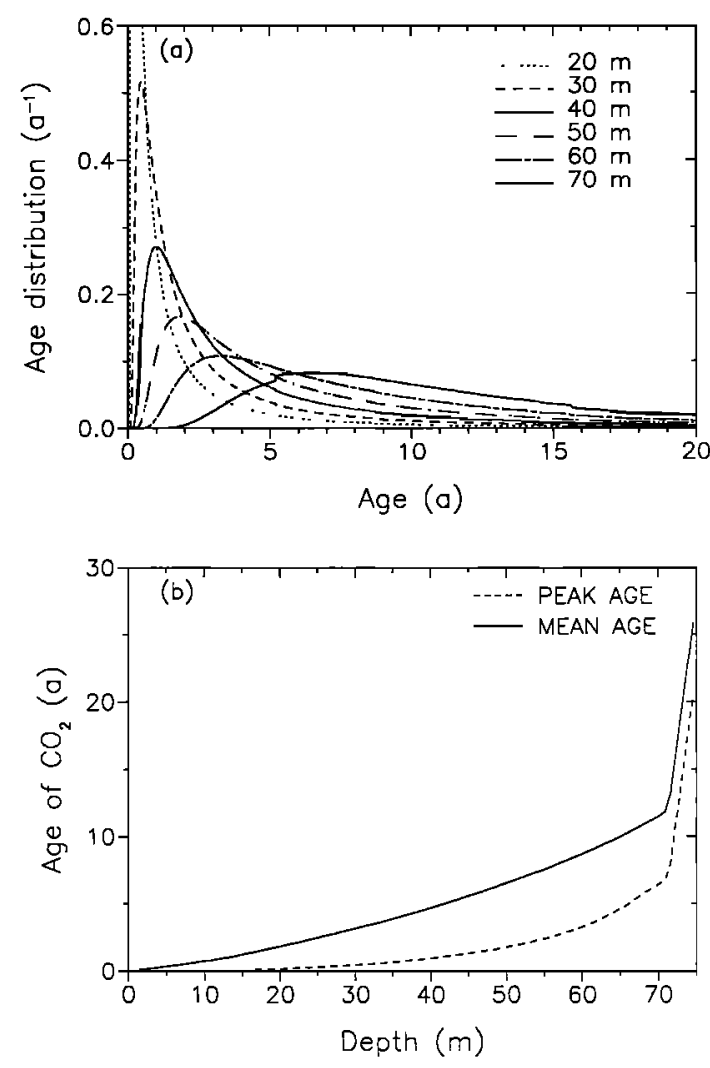

Fig. 5. (a) Age distributions for $\mathrm{CO}_{2}$ molecules at different depths as obtained from the diffusion model. The jumps in the curve for $70 \mathrm{~m}$ at 5.2 and 15.7 years have no physical meaning but are caused by the finite resolution of the model. $(b)$ Mean and most probable age of $\mathrm{CO}_{2}$ molecules versus depth.

calculated age distributions for $\mathrm{CO}_{2}$ are shown in Figure $5 a$ for several depth levels below the surface. The maximum and central values of the age distributions, i.e., the most probable and mean ages of the $\mathrm{CO}_{2}$ molecules, are shown as a function of depth in Figure $5 b$. At $70 \mathrm{~m}$, that is, near the bubble close-off depth, the distribution has a mean of 12 years and a standard deviation of 7.5 years. At this depth the ice is 220 years old. This results in a mean difference of about 210 years between the age of the ice and the age of the occluded air. To obtain the corresponding age distribution for other gases, the age scale has to be divided by the ratio of the diffusion coefficients, $D$ (gas) $/ D\left(\mathrm{CO}_{2}\right)$ as indicated in Table 1.

The model parameters cause mixing to stop below $71 \mathrm{~m}$. From Figure $2 a$, we can see that in the samples from $71-\mathrm{m}$ depth, only approximately $20 \%$ of the bubbles are formed, while the other $80 \%$ are formed in a depth where the air exchange is essentially stopped. The width of the age distribution of the air in the ice originates therefore mainly from the diffusive mixing, whereas the gradual bubble close off broadens the age distribution only to a minor degree.

\section{CONClusions}

It has been shown that at Summit Station, Greenland, the mixing of the air in the firn pores is essentially controlled by molecular diffusion. The shape of the age distribution of air enclosed in the bubbles of the ice is mainly determined by 
this diffusive mixing. It is to a minor degree broadened by the gradual close off of bubbles at the firn-ice transition, but we think that the age distribution at $70-\mathrm{m}$ depth as obtained from the diffusion model is a good assessment also for the air in the ice of deeper strata. Under present climatic conditions, the difference between the age of the ice and the mean age of the air corresponds therefore to the age of the ice at approximately $70-\mathrm{m}$ depth, that is 210 years.

A diffusion model used by the authors could be applied for other sites, as long as the snow surface is sufficiently flat, and there are no strong winds with a dominant direction, so that the effect of wind pumping is small, and the temperature is low enough that summer melting is rare. For sites with a very low accumulation rate the gradual bubble close off probably has a more important influence on the shape of the age distribution, since there the transition from firn to ice spans over a time interval that is long compared to the width of the age distribution originating from diffusive mixing.

Acknowledgments. The air sampling and ice core recovery were performed in the framework of the Eurocore project, which was supported by the EEC and Switzerland through COST 611. The laboratory work was supported by the Swiss NSF and the University of Bern and by EEC, PNEDC (Programme National sur l'Etude de la Dynamique du Climat) and CEA (Commisariat de l'Energie Atomique) in France. We thank C. Rado, J. Burkhalter, A. Fuchs, and $\mathbf{R}$. Vögtli for their technical support.

\section{REFERENCES}

Bader, H., Density of ice as a function of temperature and stress, CRREL Spec. Rep. 64, Cold Regions Res. and Eng. Lab., Hanover, N. H., 1964.

Blake, D. R., and F. S. Rowland, Continuing world-wide increase in tropospheric methane, 1978 to 1987 , Science, 239, 1129-1131, 1988.

Chanin, M.-L., D. Ehalt, P. Fraser, J. F. Frederick, J. C. Gille, M. P. McCormick, G. Mégie, and M. Schoeberl, Global trends, Scientific Assessment of Stratospheric Ozone 1989, WMO Rep. 20, World Meteorol. Organ., Geneva, 1990.

Chemical Manufacturers Association, Productions, sales and calculated release of CFC 11 and 12 through 1983, report, Flourocarbon Program Panel, Washington, D. C., 1984.

Colbeck, S. C., Air movement in snow due to windpumping, $J$. Glaciol., 35(120), 209-213, 1989.

Craig, H., Y. Horibe, and T. Sowers, Gravitational separation of gases and isotopes in polar ice caps, Science, 242, 1675-1678, 1988.

Cunnold, D. M., R. G. Prinn, R. A. Rasmussen, P. G. Simmons, F. N. Alyea, C. A. Cardelino, A. J. Crawford, P. J. Fraser, and R. D. Rosen, Atmospheric lifetime and annual release estimates for $\mathrm{CFCl}_{3}$ and $\mathrm{CF}_{2} \mathrm{Cl}_{2}$, from 5 years of ALE data, J. Geophys. Res., 91(D10), 10,797-10,817, 1986.

Ehalt, D. H., P. J. Fraser, D. Albritton, Y. Makide, R. J. Cicerone, F. S. Rowland, M. A. K. Kahlil, P. Steele, M. Legrand, and R. Zander, Trends in source gases, Report of the International Ozone Trends Panel 1988, WMO Rep. 18, World Meteorol. Organ., Geneva, 1989.

Herron, M. M., and C. C. Langway, Jr., Firn densification: An empirical model, J. Glaciol., 25, 373-385, 1980.

Jacob, D. J., M. J. Prather, S. C. Wofsy, and M. B. McElroy, Atmospheric distribution of ${ }^{85} \mathrm{Kr}$ simulated with a general circulation model, J. Geophys. Res., 92(D6), 6614-6626, 1987.

Keeling, C. D., R. B. Bacastow, A. F. Carter, S. C. Piper, T. P.
Whorf, M. Heimann, W. G. Mook, and H. Roeloffzen, A threedimensional model of atmospheric $\mathrm{CO}_{2}$ transport based on observed winds, 1 , Analysis of observational data, in Aspects of Climate Variability in the Pacific and the Western Americas, Geophys. Monogr. 55, edited by D. H. Peterson, pp. 165-236, AGU, Washington, D. C., 1989.

Landolt-Börnstein, Eigenschaften der Materie in ihren Aggregatzuständen, vol. 6, part 5a, Springer Verlag, Berlin, 1969.

Martinerie, P., D. Raynaud, D. M. Etheridge, J.-M. Barnola, and D. Mazaudier, Physical and climatic parameters which influence the air content in polar ice, Earth Planet. Sci. Lett., 112, 1-13, 1992.

Neftel, A., E. Moor, H. Oeschger, and B. Stauffer, Evidence from polar ice cores for the increase in atmospheric $\mathrm{CO}_{2}$ in the past two centuries, Nature, 315, 45-47, 1985.

Rozanski, K., Krypton-85 in the atmosphere 1950-1977: A data review, Environ. Int., 2, 139-143, 1979.

Schwander, J., The transformation of snow to ice and the occlusion of gases, in The Environmental Record in Glaciers and Ice Sheets, edited by H. Oeschger and C. C. Langway, Jr., pp. 53-67, John Wiley, New York, 1989.

Schwander, J., and B. Stauffer, Age difference between polar ice and the air trapped in its bubbles, Nature, 311, 45-47, 1984.

Schwander, J., B. Stauffer, and A. Sigg, Air mixing in firn and the age of the air at pore close-off, Ann. Glaciol., 10, 141-145, 1988.

Sowers, T., M. Bender, and D. Raynaud, Elemental and isotopic composition of occluded $\mathrm{O}_{2}$ and $\mathrm{N}_{2}$ in polar ice, J. Geophys. Res., 94(D4), 5137-5150, 1989.

Sowers, T., M. Bender, D. Raynaud, and Y. S. Korotkevich, $\delta^{15} \mathrm{~N}$ of $N_{2}$ in air trapped in polar ice: A tracer of gas transport in the firn and a possible constraint on ice age-gas age differences, $J$. Geophys. Res., 97, 15,683-15,697, 1992.

Stauffer, B., J. Schwander, and H. Oeschger, Enclosure of air during metamorphosis of dry firn to ice, Ann. Glaciol., 6, 108-112, $1985 a$.

Stauffer, B., G. Fischer, A. Neftel, and H. Oeschger, Increase of atmospheric methane recorded in Antarctic ice core, Science, 229, 1386-1388, $1985 b$.

Steele, L. P., P. J. Fraser, R. A. Rasmussen, M. A. K. Khalil, T. J. Conway, A. J. Crawford, R. H. Gammon, K. A. Masarie, and K. W. Thoning, The global distribution of methane in the troposphere, J. Atmos. Chem., 5, 125-171, 1987.

Trivett, N. B. A., and D. E. J. Worthy, Analysis and interpretation of trace gas measurements at Alert, N. W. T., with emphasis on $\mathrm{CO}_{2}$ and $\mathrm{CH}_{4}$, Extended abstracts of papers presented at the Third International Conference on Analysis and Evaluation of Atmospheric $\mathrm{CO}_{2}$ Data Present and Past, WMO Rep. 59, pp. 29-34, World Meteorol. Organ., Geneva, 1989.

Weiss, W., H. Sartorius, and H. Stockburger, Global distribution of atmospheric ${ }^{85} \mathrm{Kr}$ : A data base for the verification of transport and mixing models, in Isotopes of Noble Gases as Tracers in Environmental Studies, Panel Proc. Ser., International Atomic Energy Agency, Vienna, Austria, 1992.

Zumbrunn, R., A. Neftel, and H. Oeschger, $\mathrm{CO}_{2}$ measurements on $1-\mathrm{cm}^{3}$ ice samples with an IR laser-spectrometer (IRLS) combined with a new dry extraction device, Earth Planet. Sci. Lett., $60,318-324,1982$.

C. Andrié, LODYC/ORSTOM, Université Pierre et Marie Curie, tour 14, F-75252 Paris Cedex, France.

J.-M. Barnola and D. Raynaud, Laboratoire de Glaciologie et Géophysique de l'Environnement, BP 96, F-38402 Saint Martin d'Heres Cedex, France.

M. Leuenberger, A. Ludin, J. Schwander, and B. Stauffer, Physics Institute, University of Bern, Sidlerstrasse 5, CH-3012 Bern, Switzerland.

(Received May 12, 1992; revised September 21, 1992; accepted October 7, 1992.) 